\title{
Transforming Teacher Education Thinking: Complexity and Relational Ways of Knowing
}

\author{
KATHERINE JANE SANFORD, TIMOTHY FRANK HOPPER, AND LISA STARR \\ University of Victoria (CA)
}

\begin{abstract}
In order for teacher education programs to act as significant scaffolds in supporting new teachers to become informed, creative and innovative members of a highly complex and valuable profession, we need to re-imagine ways in which teacher education programs operate. We need to re-imagine how courses are conceptualized and connected, how learning is shared and how knowledge, not just "professional", but embedded knowledge in authentic contexts of teaching and learning is understood, shaped and re-applied. Drawing on our collective case study of instructors' lived experience of a locally developed program in secondary teacher education called Transformative University of Victoria (TRUVIC), we offer a relational approach to knowing as an alternative to more mechanistic explanations that limit teacher growth and development. To ground our interpretation, we draw on complexity as a theory of change and emergence that supports learning as distributed, relational, adaptive and emerging.
\end{abstract}

There are many ways of changing/transforming teacher education so that new teachers can understand and thrive in the complexity of today's classrooms and schools (Brouwer \& Korthagen, 2005; Cochran-Smith \& Zeichner, 2010; Korthagen, Loughran, \& Russell, 2006). For us, it has been getting in the middle of the action. For decades we have attempted to bridge the "theory/practice" divide, a chasm so wide that teacher education programs continually struggle to be seen as significant to the preparation of new teachers (Hopper \& Sanford, 2004). In this paper we build on our previous work, focusing on a school-integrated program in secondary teacher education called Transformative University of Victoria (TRUVIC). In this model of course delivery the courses in one term of a teacher education program commit to developing their course curriculum around engagement in a high school. Specifically, students in a cohort engage one day a week in 
the same school on a weekly basis with a seminar course taught in the school by teachers from the school who are hired as teacher educators. University instructors and schoolteachers collaboratively integrate course activities and assignments in relation to the school experience. We present this case study of a program innovation framed within a complexity lens.

In previous studies we focused on what we termed School Integrated Teacher Education (SITE), where Physical Education and Language Arts classes met in both elementary schools and at the university (Hopper \& Sanford, 2004, 2005, 2006, 2008). In these studies we described ways we attempted to address the gap between theory and practice, bringing classroom teachers into the discussion, including school-based activities that promote "teacherly conversations" as a significant aspect of our courses, and modeling theory/practice connections. These approaches, while offering valuable experiences, have only begun to shift the thinking about our role as educators of new teachers, as they do not permeate all aspects of the program but are fleeting, located in one or two courses, personality-driven and offering at best an innovative wedge (Wideen, Mayer-Smith, \& Moon, 1998). In order that teacher education programs act as significant scaffolds to support new teachers in their career as informed, creative and innovative members of a highly complex and valuable profession, we need to re-imagine ways in which teacher education programs operate. We need to re-imagine how courses connect, how learning is shared and how knowledge, not just "professional", but embedded knowledge in authentic contexts of teaching and learning is understood, shaped and reapplied.

\section{Critique of Teacher Education: Seeking a relational way of knowing}

Many authors have critiqued how teacher education programs and the schools they serve are built on an industrialized model of discrete courses, framed by a Cartesian worldview that separates knowledge from context and informed by a reductionist view of reality (Barab \& Plucker, 2002; Davis \& Sumara, 1997, 2006; Davis \& Sumara, 2012; Ramiah, 2014; Sanford, Williams, Hopper, \& McGregor, 2012). Typically, teacher education programs are made up of courses framed by content areas informed by disciplinary knowledge. As noted by Sanford et al., (2012) the make up of teacher education programs typically involves (1) foundational knowledge in education-related aspects of philosophy, history, educational psychology, and sociology, (2) skills in assessing student learning, using technology to support students with special needs, (3) content-area and methods for teaching a subject area, and (4) practice at classroom teaching through practicum experiences.

The knowledge and processes embedded in these areas have been developed over many decades and represent a sincere commitment to preparation of the next generation of teachers with the professional knowledge, skills and attitudes to be effective teachers. However, the way these courses are set up as separate entities, taught by an array of instructors who may have little or no connection to each other, and housed within a university competitive grading culture mitigates student preparation for taking up their role confidently. This problematic structure is further complicated by a mechanism for 
communication and evaluation of learning predicated on the power of judgment as opposed to feedback. Added to this are classrooms as learning spaces set up in rows aimed towards a single presentation screen, thus perpetuating a hierarchical teacher to student relationship and focusing on the universal knowledge, a type of knowledge that rarely applies outside the walls of the university.

In contrast, the university instructors in the TRUVIC alternative context draw on a constructivist view of learning where emphasis is on the process of co-constructing knowledge, recognizing that knowledge cannot be transmitted by the teacher to the learner. These instructors believe that learning can only take place when the learner is engaging in an active process of building and creating knowledge through participation and interaction. However, we recognize that this belief struggles to be realized. As noted by Ramiah (2014),

University teachers grapple with constructivist approaches while trying to mediate the tension of securing the 'content' of a particular discipline and imparting the key skills/competencies that learners require to communicate that content to members of their community. 'Content' and 'skills' in this sense are often associated with specific predefined objectives. These pre-defined objectives are normally ascertained through abstracting the complex knowledge of a discipline to its fundamental parts. In this way, teachers are programmed to centre their 'instruction' around predictability, patterning, control, linear-thinking and universality; ways of thinking that view the world as an ordered mechanism (p. 63).

Furthermore, these 'content' areas compete for curriculum time in order to pass on 'their' knowledge to the novice teachers in form of course lectures, activities, and assignments. Knowledge is seen as objects to be retained, repeated back, and applied within an array of assignments that serve as evaluations of understanding. Sadly, students then similarly model this structure when they enter into classroom spaces as prospective teachers, further perpetuating a style of teaching that fails to reflect the complexity and richness of learning. Successful students are rewarded with high marks within a competition for small grants and advance placement in programs. This model of teacher education perpetuates what Giroux (2005) identifies as a neoliberal discourse manifested in public schooling through testing, examinations, and projects evaluated by predetermined standards. These discourses are repeated and normalized through the processes used in the teacher education courses. All of these processes maintain students' belief in the ideology of competing for the top marks, working individually to strive for personal success. Once outside the university setting, as students become teachers, they embody these processes that continue to breathe life into a flawed system.

The structured view of the world as ordered and predictable flies in the face of the reality of rapidly developing technologies in society that demand that teachers adopt the latest innovations such as social media, smart technologies, and interactive portable devices. An array of external pressures continually push teacher educators to revise, reform, and rework their programs in response to ministry requirements, university institutional demands, the requirement of the school milieu and public popular opinion, not to mention student evaluations and internal review processes. However, we as teacher 
educators seldom stop to consider what innovation really means in relation to our teacher education programmes, the needs of our pre-service teachers, and the current professionals concerned with the education of learners for a future we cannot yet envision. Current talk in K-12 education involves much discussion of innovation in terms of $21^{\text {st }}$ century learning (Siemens \& Matheos, 2012; Trilling \& Fadel, 2009). Those conversations include renewed expectations of what knowledge, skills and dispositions students need for a future that is characterized by change more than anything else. Expectations for students include more than traditional cognitive thinking but critical and creative approaches to decision-making and collective problem solving that will enable individuals to not only live in a multi-faceted world but also actively engage in its citizenship (Schleicher, 2014). If these are the expectations for students, they must also be the expectations for teachers. Collaboration, communication and versatility are key processes but ones that cannot effectively develop in a top down structure of expert and novice. When we think of innovative practice in teacher education, we need to involve the voices and experiences of all those working in universities and in schools to enable future teachers to meet the increasingly diverse needs of all their students within their contexts of teaching and learning.

To do this, teacher education programs need to better understand the conditions that enable learning to become a teacher and consider whose voices need to be heard as we reimagine our programs, and theorize how to work in the spaces of schools to become 'students of teaching' (Dewey, 1904; Loughran, 2006). While contextual variables such as institutional time-tables and student populations demand flexibility and adaptability in programming, core elements of innovative practice and meaningful teacher education programs can co-exist, in partnerships between schools and universities, that enable teachers to thrive in ever-changing environments.

\section{Relational view of knowing}

This critique of teacher education is not unique; a similar concern is voiced in relation to all types of professional programs within a university culture (Buckley et al., 2009; Russell, McPherson, \& Martin, 2001; Siemens \& Matheos, 2012). The critique of Cartesian dualism with the resulting Newtonian mechanistic view of reality and the associated separation of mind from body, of knowledge from context, has led to a rethinking of how we know what we know and how we understand learning (Capra \& Luigi Luisi, 2014). Agreeing with contemporary learning theorists such as Barab \& Plucker (2002) we have come to the conclusion that we need to consider a relational approach to knowing that is an alternative to more mechanistic explanations. Such a perspective frames human learning and the cognitive processes it entails as distributed in the world and our interactions in that world. As Barab and Plucker note, referencing Salomon (1993),

understanding of human cognition would be achieved if studies were based on the concept that cognition is distributed among individuals, that knowledge is socially constructed through collaborative efforts to achieve shared objectives in cultural surroundings, and that information is processed between individuals and the tools and artifacts provided by culture. (p. 166) 
Furthermore, this relational view of reality proposes knowledge forming from what Lysaker and Furuness (2011) term as a relational epistemology. As they state, drawing on Belenky, Clinchy, Goldberger, and Tarule (1986),

.... relational view of knowing and knowledge is grounded in the idea that we come into being in and through relationship (Belenky, Clinchy, Goldberger, \& Tarule, 1986). All knowing and learning comes from our human need for connection with others and with the world. Given this epistemic stance, it follows that our knowledge of the world is mediated by our relationships with those around us, particularly those to whom we are most attached. (p. 187)

In turn, relational pedagogy requires that we, as teacher educators, value and respect learners' prior knowledge and their style of learning as well as support students to make connections between theory and personal experience (Brownlee \& Berthelsen, 2008). To do this, we create opportunities for relational pedagogy where students are active meaning makers with us to create a curriculum of teaching and learning based on lived experience shared equally by teacher and student (Giles, 2011; Riley-Taylor, 2002).

\section{Data sources of case study}

As noted by Stake (2005), this paper presents a qualitative, intrinsic case study drawing on the shared 'lived experiences' of eight instructors participating in the TRUVIC program innovation. The insight here is developed from meetings and interviews with instructors (five university-based instructors; including one practicum supervisor, and three schoolteacher-instructors). Data came in the form of meeting notes, one instructor's personal anecdotal account of setting up the project, instructors' accounts of student responses, common principles used by instructors in integrating courses and field experiences, and storied accounts and examples shared by instructors about the project. Participants' data was voluntarily collected with signed consent on forms passed by the human research ethics board at the university. Additional data in the form of images and video clips on the project from students, administrators, teachers and ministry representative can be found at the publicly available website on the project (Sanford, 2012). This website offers evidence of the changing relational pedagogy that developed in the TRUVIC project and the transformative thinking and positive responses from those involved. Instructor data was collected, indexed and shared in the form of anecdotal accounts to generate this final paper. Our goal in this paper is not to represent a generalized account, or even an objective account triangulated by multiple forms of evidence; rather, as Horn (2008) describes, we focus on the "social interactions" within the TRUVIC project "system" as noted by the instructors, who offer a way to imagine an emerging new space for teacher education. The paper offers a phenomenological account of the instructors' growing awareness of how the TRUVIC project shifted a collection of courses in one term of a teacher education program from reductionist to a more relational pedagogy.

In the following section the initiator of the project reflects on her account of starting TRUVIC. This account has been shared and revised in consultation with colleagues. Her account in italics sets the context for the analysis for how a complex learning system 
formed around the project. From her insights we build in the theoretical ideas from complexity science that support framing pedagogy in relational ways of knowing

Reflection 1: In the beginning...

As I was teaching my secondary English majors one day, preparing them for their future practicum, I realized how inadequate I was to help them navigate the challenges of teaching English in any high school. First, I was teaching them in isolation from adolescents, or the messiness of school, or the reality that faced them - small classrooms, too many students, diverse student interests, needs, and hopes - in a practicum situation. Second, I had no idea what other course instructors were going to say to them, whether it would support my teachings or refute them. Third, to be honest, without the regular contact with adolescents in high school classrooms, I had lost touch with the needs and interests of adolescents in all their complexity, and was not able to adequately convey to my students the conditions they would be facing as I myself did not know. Also, I was aware that the mantra from high school teachers when they reached their practicum was "Forget everything they taught you in the ivory tower - I will teach you what you really need to know!"

How, then, was I going to make my time with the students of any value at all? How was I going to change the fragmentation, multiple conflicting messages, excessive assignments that students could not see as useful to their success in the classroom, or the age-old theory/practice divide?

I decided I needed to try. At the same time, I had the good fortune to be working with a teacher who was completing his Masters' degree with me. He also had ideas about how to improve the teacher education program, and we began talking about creating a 'teaching school' where we could work collaboratively to more effectively prepare our next generation of teachers, his future colleagues. So it began...

Changing the condition for TRUVIC to emerge as a complex learning system

To help describe the TRUVIC learning as distributed, relational, adaptive and emerging we have drawn on complexity theory. Complexity theory (CT) has its origins in chemistry, physics, information science, cybernetics, and systems theory and focuses on describing change. CT has brought a range of disparate ideas together and challenges the pervasive worldview built on scientific reductionism "where complex phenomena can be understood entirely from the properties of its parts" (Capra \& Luisi, 2014, p. 64). Complexity theory is a theory of change and emergence; it is "about the dynamics of change within a system" (Ramiah, 2014, p. 64). CT focuses on the interaction of the parts of a living or social system to evolve and adapt, often in the interest of survival or to thrive, through a combination of co-operation and competition (Kauffmann, 1995; Mason, 2008; Morrison, 2008). Complex systems can be seen as ant colonies, human brains, cities, immune systems--all [of which] turn out to follow the rules of emergence (Johnson, 2001). Complexity theory was used to guide changes made in the clutter of courses in the TRUVIC project that allowed a complex system to develop built on a commitment to a relational pedagogy of knowing (Lysaker \& Furuness, 2011). 
Reflection 2: Creating the conditions for cross-course relations

I was fortunate to have had administrative experience within my faculty, so I was aware of how the structures worked, i.e., timetabling, assignment of instructors, and alignment of student schedules. Students took six courses each term, followed by a practicum. Even so, it was challenging getting these structural issues to line up so we could effectively address the issues of fragmentation, lack of collaboration/communication, and disconnect between university and school. I wanted to work with other instructors who would be willing to work collaboratively --- one of the students' biggest concerns was what they termed 'overlap' - every instructor was giving the similar information or the same type of assignment, and unaware that they were doing so. In order to maximize the short amount of time we each had with the students (3 hours a week for 13 weeks), we needed to work together, to share assignments, to support each others' ideas and expand upon them, rather than reiterating the same things five times over in each class. Additionally, we needed to find a way to introduce the school culture to our students at the beginning of their program, so that the assignments they were completing were supported by and supporting their preparation for teaching.

\section{Relational Indigenous Teaching and Learning Principles}

The TRUVIC project can be understood as a complex collective unity; a system that encourages transformation of all members (student teachers, teachers and instructors) in their trajectories as teachers. The initial conditions for the project focused on setting up ongoing communication between instructors/teachers, to share ideas that then shaped subsequent planning. The instructors/teachers learned to draw on each other's diverse abilities and contexts, with the schoolteachers and university instructors sharing a common goal to educate the student teachers in a relational pedagogy through situated experiences in the school and community. The first structural change agreed upon by the course instructors was to use a contract grading system. This system encouraged students to reach professional quality work for a pass and then to submit a proposal for extension assignments that they would do for higher marks. The second change was to focus the interaction on the student teachers, and to counteract the ideology of competition for marks; to accomplish this the instructors promoted three indigenous teaching and learning principles. These principles and others are explained more fully in Sanford et al., (2012). To help students to maximize their learning and the learning of their community the following three principles were introduced to the students.

(1) Put the learning of your peers before your own learning.

(2) Create work that will benefit seven generations to come.

(3) Find your own passion in the course content and use it to energize the community. (p.

Adopting these principles is about being relationally accountable. Wilson (2008) suggests that relational accountability places meaning and significance on the relationships that go into forming concepts or ideas before the concepts and ideas themselves. While neither can exist in isolation of the other, the relationships are central. Kirkness and Barnhardt (1991) describe relational accountability as being enacted through practicing respect, 
relevance, reciprocity, and responsibility. For Wilson (2008) and Kirkness and Barnhardt (1991), the use of relational accountability relates to an Indigenist paradigm. Our intent is not to appropriate Indigenous learning or knowledge, instead we seek to imbue relationality in our interactions and learning. To further explain our use of these Indigenous teaching and learning principles, we offer Wilson's (2007) explanation.

It is my belief that an Indigenist paradigm can be used by anyone who chooses to follow its tenets. It cannot and should not be claimed to belong only to people with 'Aboriginal' heritage. To use an analogy, one does not need to be female to be a feminist. Researchers do not have to be Indigenous to use an Indigenist paradigm just as researchers do not have to be "white" to use a Western paradigm. (p. 4)

In using the Indigenous principles for teaching and learning, our intent is to acknowledge that being relationally accountable is grounded in a tradition where knowledge is about relationships. "Rather than viewing ourselves as being in relationship with other people or things, we are the relationships that we hold and are part of (Wilson, 2008, p. 80).

Our perspectives have led us to consider learning, and in particular learning in a teacher education program, as no longer an act of capturing information or a process of meaning construction. Rather, learning is situated in a professional context (Lave \& Wenger, 1991) and as a process of adaptation and evolution that emerges through the learner's interactions with a dynamic and responsive environment (Davis \& Sumara, 2012). To activate this, situated learning within a complex system a dynamic was created between student learning and tasks focused on learning in context and school environment.

Reflection 3: One day a week students visited the school, observed and participated in the classes

One of the first-term courses was a seminar that consisted of a series of discrete workshops offering information about professional role, planning, curriculum documents and teacher identity. In consultation with the department administrator I was able to shift the teaching of that seminar both to the school as the site, and a school-based teacher as the seminar instructor, and to devote one day a week to students' visiting the school, observing and participating in the classes, and gradually working with high school students. Starting at 7:45 each Wednesday morning, students met with their seminar instructors (who were also teachers in the school) who established the focus for the day, organized the classroom visits, shared insights and school news from the previous week. At the end of the day, they would teach the seminar, enabling immediate debriefing of their observations and focus on issues of currency in the school. These seminars enabled students to begin to immerse themselves in the culture of high school, gain a sense of adolescents (from a teacher perspective), and to have opportunities to talk with practicing teachers about their realities. They also had opportunities, during the other four days of the week, to connect their classes with the school-based experiences, and to challenge the ideas being received from both the school and the campus. The fact that the seminar instructors were also part of the school staff as insiders enabled students and university instructors access to the school in a way that outsiders could never have achieved. This was a key factor in enabling students to visit a variety of classrooms in the school, 
as the seminar instructors (as teachers in the school) were able to provide the credibility with colleagues needed for such engagement.

Changing the location for a teacher complex learning system to evolve

Traditional thinking on how institutions such as schools and universities operate is based on an ideology focused on order and routine method that seeks to predict and control. This ideology permeates all aspects of teaching and learning. CT challenges this ideology as it assumes the whole is greater than the sum of its parts. As Capra and Luisi (2014) note, CT focuses attention on how the interactions and products of the interconnecting parts allows emergence of "novelty that is often qualitatively different from the phenomena out of which is emerged" (p. 261). This then creates a renewing process that changes the system from which the emergence happened as well as influencing the environment in which the emergence arose. The relations formed between the instructors, courses, university-school and course-content/field experiences created a catalyst for learning to emerge that focused on "being" a teacher, "thinking" like a teacher and "acting" like a teacher; gradually the need to act like a student in an isolated course in a fragmented program with content delivered to be test, faded away.

Reflection 4: Students were immersed, a day each week, in the school

The students' day in the school also enabled them to begin to practice teaching, at first in nonthreatening ways (one-on-one support of struggling learners, peer teaching, team-teaching with a teacher) and then gradually increasing their involvement as their confidence developed. They were able to practice ideas they gained in their campus courses, as well as develop a sense of their teacher selves they had only previously imagined.

As the students were working in a cohort, all taking the same classes and visiting the same school, they had an immediate and present support group who were working through the same issues and challenges. This became beneficial very early in the term, as they began to recognize the complexities of their chosen profession and to feel somewhat overwhelmed at the prospect of preparing themselves to face the challenges. Students quickly developed their own mechanisms for interacting 'behind the scenes', such as creating a Facebook page, socializing after class, sharing ideas and sharing fears. The discussion forum, intended for students to explore questions and concerns beyond the scope of any one class, began to be used for exchanging stories, strategies, and concerns.

Field trips to other schools and community sites supplemented the weekly visits to their regular high school, broadening and challenging the students' collective ideas on curriculum and their local community. Optional visits to alternative programs, independent schools, middle schools, local public library, archives, cemetery, and museum offered ideas about ways to integrate community institutions and events into classroom activities. Additionally, instructors from across campus were invited to share their expertise in relation to teaching Shakespeare, using story drama, developing electronic portfolios, 'gamifying' education, visiting the museum to view Indigenous language exhibits, and community mapping, to name a few examples. 


\section{Students selecting to have an experience that transforms them}

The essential elements of a complex system are that it is emergent, adaptive and selforganizing. Once a complex system, interacting with the environment that affords its coherence, reaches a certain critical level of diversity and interaction between its parts, it self-organizes in a continuous activity drawing on available resources, as its parts act together and in turn interconnect with the environment. Different environments afforded different opportunities for different student teachers to grow and develop. As noted by Capra (1996) "interactions of a living organism - plant, animal, or human - with its environment are cognitive interactions...living system couple to its environment structurally - that is, through recurrent interactions" (p. 172). This means that, as Proulx (2008, p. 16) notes, "changes in an organism [learner] are dependent on, but not determined by, the environment", and that "the environment does not act as a selector, but mainly as a "trigger"" as the learner becomes structurally coupled to the environment through recurrent and reciprocal adaptations and transformations. Using the term 'complexity thinking', Davis and Sumara (2006) have applied CT to learning in this way, focusing on adaptive, self-organizing systems where learning emerges from experiences that trigger transformations in learners and in the environments they bring forth through their interactions. These ideas, then, lead us to consider further, what are the shifts that can be made in the initial conditions for teacher education that we create for student teachers that will allow teacher education and the practice of teaching in schools to evolve as a complex system that adapts to the needs of all students as complex entities?

\section{Reflection 5: Shifts in role as instructor}

One of the most profound shifts in the teacher education program was the willingness of most of the course instructors (although never all of them) to collaborate, share ideas, and develop assignments together. Beginning several months before the term commenced, I invited instructors to gather to develop common goals, talk about their intentions for assisting students to achieve those goals, and to ensure that all would be working with the same educational principles. Through several meetings, all instructors involved, including myself, were able to shift their own thinking, align their ideas, and often reduce the number of assignments, recognizing that students would be overwhelmed by all of the individual ideas we were planning to bring to them. Once the term began, we continued to meet and adapt assignments and due dates in order to respond to feedback from the students. We visited each other's classes throughout the term, which modeled collaborative thinking and practice for our students. We all got to know the students much more intimately than if we had only been teaching our own classes, especially through the field trips, visits to the school, and connecting with each other about students' individual and specific needs. Most of all, we had fun together and with the students. The learning in TRUVIC became distributed across courses and school/field experiences. Knowledge to be a teacher became relationally focused between students, instructors and schoolteachers, adaptive to school experiences and responsive to emergent issues and events. 


\section{Creating conditions for complex learning to emerge}

Recognizing the TRUVIC project, made up of four courses connected by a shared field experiences and instructors who continually collaborated and coordinated assignments, allowed us to consider how features of a complex system started to develop in the project. From a CT perspective learning evolves in a non-linear form from discovery in relation to exploration, reflection, action, sharing and refocusing as learners collectively self-organize around a common intent and a forming social identity. Such learning encourages a form of systems thinking that allows both living and social systems to be made of "integrated wholes whose essential properties arise from the relationships between its parts, and 'systems thinking', the understanding of a phenomenon within the context of a larger whole" (Capra \& Luisi, 2014, p.64). For this to happen the conditions have to be created for certain features of a complex system to emerge. As noted by Davis and Sumara (2006) and adapted by Ramiah (2014) complex systems demonstrate these features:

1. Self-organized -- complex systems are unities that spontaneously arise through the actions of autonomous members who come to be interlinked and codependent as they interact with each other and transform themselves through collective action that is not centrally controlled;

2. Bottom-up emergent -- complex unities that manifest properties exceeding the summed traits and capacities of members of the group, but these qualities and capacities do not depend on a governing top-down structure;

3. Short-range relationships -- most of the information within a complex system is exchanged between close neighbors, meaning that the system's coherence depends mostly on members' interactions, not on centralized control or top-down administration;

4. Nested structure -- complex unities such as social groups are composed of other complex unities such as individual people, whose interactions give rise to new patterns of activities and behavior;

5. Ambiguously bounded - complex forms are open in the sense that they are continuously exchanging matter and energy with their surroundings, adapting to feedback loops in the collective system, avoiding any strict boundaries as they are constantly in a state of flux with their surroundings;

6. Organizationally closed -- although members of a complex system are constantly interacting with their neighbours as a complex form they are closed in the sense that they are inherently stable; that is, their identity endures, even while they exchange energy and matter with their dynamic contexts;

7. Structurally determined -- a complex system behaviour is determined by its structure; "a structure formed by a succession of autonomous structural changes" (Capra \& Luisi, 2014, p. 136), but it can change its own structure as it adapts to maintain its viability within dynamic contexts; in other words, complex systems embody their histories -- they learn and evolve in order to survive and thrive;

8. Far-from equilibrium -- complex systems are not stable, do not operate in balance, they are always in a dynamic with other systems. Stable equilibrium implies death for a complex system. 
For these features to arise, certain conditions need to be present within university courses (Davis \& Sumara, 2006; Hopper, 2013). Critically, for a complex system to emerge there must contain enough diversity in its make-up to allow it the ability to adapt to demands of the environment, but there must also be enough redundancy (commonality) between members to maintain coherence (shared understandings) and the ability to adapt to stress from participation in the environment. Knowledge and skills emerge in co-mingling of roles associated with the intents of the system as members of the system interact with each other. Davis and Sumara (2006) propose that to enable such interactions "one must relinquish any desire to control...control in a knowledge-producing collective must be understood as decentralized, arising in local activities" (p. 144). Teacher-directed activities are to be precluded, but rather that the decentralized structure is valuable as it allows for the possibility of emergence. The conditions in the environment need to offer enabling constraints that limit what the system can do to prevent it being overwhelmed but at the same time offer an openness to possibilities, sources of randomness that require the learning system to adapt. Through a process of recursive elaboration and continuous feedback loops the system forms nested structures that emerge from inter-actions around simple rules that initiated the system's ability to adapt and dynamically unfold.

The initial conditions of the project allowed the cluster of six courses to become increasingly inter-acted and nested in shared experiences. Table 1 offers examples of how the conditions set up in the TRUVIC project allowed key features of complexity system to emerge. In each case the complexity feature is listed, key aspects noted, and then examples for the instructors and the student teachers.

\section{Table 1}

Mapping the features of complexity theory applied to TRUVIC project

\begin{tabular}{|c|c|c|}
\hline Term & Key aspects & Some examples from TRUVIC \\
\hline \multirow{2}{*}{$\begin{array}{l}\text { Self- } \\
\text { organized }\end{array}$} & \multirow[t]{2}{*}{$\begin{array}{l}\text { - Interactions to } \\
\text { transform } \\
\text { - Not centrally } \\
\text { controlled }\end{array}$} & $\begin{array}{l}\text { Three formal instructor meetings throughout term to frame } \\
\text { assignments and course expectations. Courses organized in } \\
\text { relation to each other and field experiences as negotiated } \\
\text { curricula emerged. }\end{array}$ \\
\hline & & $\begin{array}{l}\text { Course drew on same educational principles that allowed } \\
\text { students to build a coherent sense of educational purpose as } \\
\text { they increasingly negotiated course curricula. }\end{array}$ \\
\hline \multirow{2}{*}{$\begin{array}{l}\text { Bottom-up } \\
\text { emergent } \\
\text { qualities }\end{array}$} & \multirow{2}{*}{$\begin{array}{l}\text { - Qualities arise from } \\
\text { synergy of } \\
\text { individual courses } \\
\text { (parts). } \\
\text { - Adaptive in relation } \\
\text { to diversity } \\
\text { - Decentralized } \\
\text { control. }\end{array}$} & $\begin{array}{l}\text { Instructors collaborate across courses to design a common } \\
\text { curriculum related to content areas but anchored to } \\
\text { experiences in the school. }\end{array}$ \\
\hline & & $\begin{array}{l}\text { Students connected through informal networks (i.e. } \\
\text { Facebook), sharing and exchanging stories, strategies, and } \\
\text { concerns to address challenges. }\end{array}$ \\
\hline $\begin{array}{l}\text { Short-range } \\
\text { relationships }\end{array}$ & $\begin{array}{l}\text { - Information from } \\
\text { group coherence }\end{array}$ & $\begin{array}{l}\text { Ongoing connection between instructors and school } \\
\text { teachers through email, informal chats and school visits. }\end{array}$ \\
\hline
\end{tabular}




\begin{tabular}{|c|c|c|}
\hline & $\begin{array}{l}\text { - Close neighborly } \\
\text { interactions }\end{array}$ & $\begin{array}{l}\text { Cohort promotes friendships in social experiences as well as } \\
\text { in courses. Shared cross-course electronic forums allow } \\
\text { coherence to form. Joint activities promote discussions and } \\
\text { multi-perspectives on experiences. }\end{array}$ \\
\hline \multirow{2}{*}{$\begin{array}{l}\text { Nested } \\
\text { structure }\end{array}$} & \multirow{2}{*}{$\begin{array}{l}\text { - Students nested in } \\
\text { courses within } \\
\text { programs within } \\
\text { faculty. } \\
\text { - Enable systems } \\
\text { thinking }\end{array}$} & $\begin{array}{l}\text { Courses nested in university and school culture expanded } \\
\text { scope and application. Allowed content to become } \\
\text { connected to authentic reality of schools. }\end{array}$ \\
\hline & & $\begin{array}{l}\text { Students interact with past students who now, as teachers, } \\
\text { help them to see connections of different systems enabling } \\
\text { them to imagine and act as educational leaders }\end{array}$ \\
\hline \multirow[b]{2}{*}{$\begin{array}{l}\text { Ambiguously } \\
\text { bounded }\end{array}$} & \multirow{2}{*}{$\begin{array}{l}\text { - Complex forms } \\
\text { open } \\
\text { - In flux with } \\
\text { surroundings } \\
\text { - Adapting through } \\
\text { feedback loops }\end{array}$} & $\begin{array}{l}\text { Course content became more open to school experiences and } \\
\text { other courses. }\end{array}$ \\
\hline & & $\begin{array}{l}\text { Constant negotiation of meaning of concepts to school } \\
\text { experiences and students' own past as students. }\end{array}$ \\
\hline \multirow{2}{*}{$\begin{array}{l}\text { Organizationa } \\
\text { lly closed }\end{array}$} & \multirow{2}{*}{$\begin{array}{l}\text { - Retain own identity } \\
\text { - Constantly } \\
\text { interacting } \\
\text { - Exchange energy } \\
\text { and matter with } \\
\text { their dynamic } \\
\text { contexts. }\end{array}$} & $\begin{array}{l}\text { Courses maintain focus on content area but learning was } \\
\text { driven by inter-relationships to school and related field } \\
\text { trips, exponentially expanded scope of content. }\end{array}$ \\
\hline & & $\begin{array}{l}\text { Students formed a common understanding of becoming a } \\
\text { teacher whilst maintaining their sense of being teacher. }\end{array}$ \\
\hline \multirow{2}{*}{$\begin{array}{l}\text { Structurally } \\
\text { determined }\end{array}$} & \multirow{2}{*}{$\begin{array}{l}\text { - Behaviour limited } \\
\text { by structure } \\
\text { - To survive change } \\
\text { from successive } \\
\text { autonomous } \\
\text { restructuring }\end{array}$} & $\begin{array}{l}\text { Reduce number of assignments, focused on cross-course } \\
\text { learning as students are seen as learners transforming as } \\
\text { integrating learning across courses over time. }\end{array}$ \\
\hline & & $\begin{array}{l}\text { Self-referencing nature of assignments allowed students to } \\
\text { reflect on own learning, readiness to learn. With extension } \\
\text { assignments students designed and shared own learning. }\end{array}$ \\
\hline $\begin{array}{l}\text { Far-from } \\
\text { equilibrium }\end{array}$ & $\begin{array}{l}\text { - Always in flux } \\
\text { - Stable equilibrium } \\
\text { implies death of } \\
\text { complex system }\end{array}$ & $\begin{array}{l}\text { Curriculum of course became increasingly dynamic and } \\
\text { responsive to student experiences with timetable adapted to } \\
\text { allow extended time for field trips and special events. }\end{array}$ \\
\hline
\end{tabular}

Table 1 captures how the structure of the TRUVIC program initiative evolved first as an emergent idea and then increasingly by design as aspects of complexity thinking were applied to timetabling the courses, working with colleagues and reshaping tasks/assignments to focus on learning from the situated, relational and school centred experiences. The final section summarizes key ideas expressed by instructors through meetings, interviews and written reflections. This final section offers insight into the TRUVIC group's thinking, planning and growing awareness of the project and how to improve it.

\section{TRUVIC from inception to current understanding}

The first year of this initiative involved a group of 16 students, all taking the same courses. As the other students in the program recognized the merits of this approach, it expanded 
to include all of the seventy students in the post-degree secondary program in the second year, two cohorts working at two different high schools in the local area. In the third year, we have also included the students in a concurrent B.Ed. program, expanding to four cohorts working at local schools, over 100 students. There have been ongoing changes and modifications to the initiative, in addition to the size of the group involved. Assignments have been adapted to better meet the needs of the students. For example, in the first year a student suggested that the teaching experiences being required in the school needed more structure and so she wrote an assignment that would better capture students' needs. We adopted her suggestions for the second year. A student in the second year of the initiative rewrote the course outline, using a student perspective to describe the connections and expectations of the instructors involved in the program. Also as a result of students' feedback, we then paired the students so they have a 'critical friend' to navigate the school experience with and to share informal reflections and questions. The students also suggested having more opportunities to debrief at the end of their day in the school, and to build in breaks so they would have time to reflect upon the myriad observations and experiences they were having throughout their days. All of these suggestions were discussed and implemented for the following year.

As this initiative has continued at the same school sites, there has been a recursive elaborative process of interactions forming that were not initially planned. Student teachers who have completed the program are now substitute teaching at the school, offering opportunities for current student teachers to interact with them. In one day they might visit a class with a graduated student teacher teaching the class, a final term student teacher completing a practicum, and their own peers in the school. These encounters enable new teachers to teach the new student teachers, model teaching of the class they now teach regularly, and have conversations with the new student teachers about their own experiences, sharing ideas and strategies in a nested form of system thinking about teaching. Students involved in the school are also invited to professional development sessions and welcomed into professional learning communities (PLCs) that exist within and beyond the school. On several occasions student teachers have presented at local and national conferences about their own research and their involvement in this teacher education initiative.

Not only have the students in the teacher education program learned. The instructors have had repeated and ongoing meaningful encounters with each other, sharing ideas, adapting their own practices, and in turn influencing each other. As the program has developed, participants (both instructors and students) have become more articulate about their involvement in this social constructivist approach to learning and to developing as teachers/teacher educators. Policy-makers have also been invited into the conversation to talk with the students, the instructors, and with university administrators about shared educational ideas and goals. As a result of participation in and study of the TRUVIC experience, the instructors have been able to highlight several key understandings: the value of slow immersive learning, the process of negotiating collaborative meaning and practice, the importance of the cohort model in enabling the conditions for learning, and the worth of fostering learning in multiple settings. 


\section{Our emerging understandings: Reflecting on slow immersive learning}

Learning anything meaningful and worthwhile takes time and focused energy. As instructors, we must attend to the recursiveness of learning and to plan for the interconnection of ideas that will emerge. Ideas planted in the first meeting with our student teachers can be developed over time. In our first meeting with students in the initial year of this TRUVIC program, we met with the students together. In a circle, we started the class, sixteen students and eight instructors; the three seminar instructors were teaching in their school at the time, so they all recorded short videos introducing themselves. There was a sense of incredulity in the room as the students were wondering what was going on - this was not how they had previously experienced the start of classes. We began all introducing ourselves, and then describing how we imagined the term would unfold - shared assignments, sustained work in the schools, working together with all of their courses. We reviewed the courses and how they would be interconnected, and we shared the assignments they would focus on. We shared why we were changing the structure of the program and what we hoped would be gained by the end of the term. There were nods from the students, but also concerned looks and some anxious glances as they viewed the room full of people they would work with closely over the next three months. At the end of the class they left, quiet and pensive. Our approach and subsequent explanation was radically different from how many of these students had experienced and envisioned education. To embrace such a departure requires trust and confidence that this complex, relational approach to learning was both credible and worthwhile. As instructors, our responsibility was to ensure that the students felt supported and encouraged as they embarked together, in their learning to become teachers.

At the end of the term we met with each of the students individually to get their feedback about their experiences. Some of them laughed, remembering their first encounter and the thoughts that were going through their heads. Others talked about the difficulty they had in embracing this collaborative model of learning, talking about their confusion, their concern about being successful (they were all motivated 'good' students), and their ability to work with adolescents. One student commented that she was anxious for about three weeks, at which point she just decided to take the leap and take advantage of the opportunities to work with students and teachers, to integrate her assignments, to challenge herself and to "embrace the chaos".

The term culminated with a 'gallery walk', in which they shared the results of the inquiry question they had identified throughout the term. The gallery walk was a place to demonstrate their integrated learning throughout the term, drawing on ideas, strategies, and questions explored by their instructors throughout the term and building on an issue of significant interest/passion to them. The gallery walk was held in a large classroom in the high school at the end of the term, where the students displayed an artifact representing their learning, i.e., posterboard, video, sculpture, etc. All of the instructors attended, as well as members from the school district administration, Ministry of Education representatives, other teachers and students from the school, and friends and family. The room was buzzing with excited chatter as the students set up their work, aware that they would be asked questions about their inquiry and their developing 
understandings. Throughout the afternoon, they responded to many questions and suggestions, engaging in meaningful professional conversations and sharing insights. They recognized their ability to share their knowledge, and they also recognized that they had learned a great deal throughout the term and were able to draw on and articulate what they had learned from their various campus-based and school-based classes. They learned to adapt their knowledge effectively in different ways to different audiences as they responded to a wide range of questions. They left that afternoon with pride and only a disappointment that they hadn't had longer to share their work.

\section{Collaboration/negotiated meanings and practice}

Collaboration is hard work. After coming up with this idea for changing the structure of the term, we had to negotiate what it would actually look like for the students and ourselves so we could sustain it throughout the term. But first we had to come to know and trust each other which required setting aside ego. We met in the school conference room, and at first we were polite and respectful as each other spoke, but then ideas began flowing. The teachers who were taking up the role of seminar instructors were quietly watching, waiting for recognition and evidence that they would be taken seriously. They had experienced 'partnerships' with university before, but had not always felt that their experience carried equal weight. Teachers in the school could not meet the student teachers at the beginning of the program orientation as they were teaching in the school. So when the idea of creating videos came up, as a way that the teacher/instructors could participate in our first meeting, it became clearer that everyone's voice would be equally valued and respected in the group, that the teachers presence at the university we seen as important. Jokes were made about what the videos would look like, and ideas were shared.

After many years of working in isolation, planning and teaching independently, revealing our ideas and ourselves was challenging. At first we were tentative, sharing possibilities and ways that we could connect across courses. There was confusion, as some were talking at cross-purposes with others, using terms that everyone wasn't familiar with. There were structural barriers we still had to overcome, related to space, timing, instructor availability, as well as understanding each other's work realities. We had ideas about what had worked well in the past, and that we didn't want to let go. Some activities were institutionalized, such as lesson and unit planning, and we all had a vested interest in ensuring our students were well informed about our individual content areas.

Gradually, however, as we continued talking, we began to see ways in which we could shift our own practices to connect to others. We gained new ideas from listening to our colleagues and were able to let go of some of our entrenched ideas as we saw how combining our efforts would lead to stronger learning experiences for our students. For example, planning assignments became real as lessons were drafted at university and then implemented and reflected upon in the school. Teachers in the school created opportunities for student teachers to teach in their units, expecting them to be in the school on a regular basis throughout the term. 


\section{Shared responsibility}

In all of our conversations, collaborative as they were, we had not initially included our students. If, as we suggested to our students in the first meeting, we were attempting to respond to their needs as they learned to become teachers, we needed to listen well to their ideas and concerns. As we developed relationships with the students, they became more willing to share with us and as a result, assignments were adapted, activities were added (or removed), and the curriculum emerged differently than we had initially planned it. A 'community meeting' was held at the end of each month at the conclusion of the seminar class, and all instructors came to listen to students' perspectives on "how things were going" as part of an adaptive feedback loop for program design. In some cases, what was said was uncomfortable for the instructors as students suggested what wasn't working for them, what they would like to see, and how they envisioned their learning. The conversation was public so instructors had to take responsibility for recognizing what wasn't working and try to change. Students also had to take responsibility; they couldn't hide behind anonymous comments in sharing their perspectives. As the term continued, the students took more responsibility for their own learning and became easier in asking questions, making suggestions, and adapting their assignments to better suit their needs. In sharing the responsibility, it also took the instructors considerable time in adapting and planning for new ideas. We would meet regularly in informal conversations to figure out ways to respond, to share class time, to switch times and spaces. Collaboration in institutional structures is not easy, and the artificial time and room allocations were continually being manipulated in creative ways. The will to collaborate, we recognized, must be present in order to involve all partners (including the students) in the program planning.

Instructors were, in most cases, using a system of assessment we have called contract grading with extension assignments (as introduced earlier in the paper). Recognizing that grading was a serious detriment to student collaboration and sharing, and to create a focus on learning rather than grading, we adopted an approach that identified a standard acceptable grade for all of our students. In a professional program, our goal is to ensure that all students are achieving the best possible results for working with school students. However, we also recognize that some students are 1) interested in investing more time into an aspect of their learning and want that recognized, or 2) committed to higher learning and want the opportunity to achieve and have it recognized by a higher grade. About half of the students regularly opt for completing an "extension" assignment which results in a higher grade - the caveat of completing these assignments is that (drawing on Indigenous principles of learning) their work must benefit their community as well as themselves. They are then required to share their extension projects with their peers and instructors. In one case, a student elected to research the program itself, so she interviewed her peers, examined documents, and created a report demonstrating her findings. She also shared her work at a teacher education conference. 
Power of cohorts

Cohorts, especially those not required to compete with one another, create powerful support groups and professional learning communities. Surprising to us, the initial cohort we worked with, a disparate group of people who previously did not know each other, and who had different backgrounds, interests, and aspirations, connected with each other very quickly. Initially through class experiences and opportunities, and then through selforganized activities, they formed a tight and supportive group. In the first year, we all went on a day-long field trip to another local community to visit the school and experience their innovative practices. We took a photo of the group on a small ferry, all waving at the camera and looking happy, that is still embedded in our memories (Sanford, 2012). One of the instructors took the group to a local park to view the salmon spawning, and many of the students elected to extend the visit, camping overnight in the rain (the instructors, needless to say, did not stay!).

In each of the years, the instructors have identified, or followed up on interests of students, to organize field trips - last year we went to an historic cemetery to better understand the cultural background of previous generations, to recognize the value of involving students in their community, and to understand how to plan a field trip. Other field trips have taken us to the art gallery, the public library and archives, alternative schools, independent/private schools, and middle schools. For each of these events, students have organized car-pooling, met together, and learned more about each other. These activities also spawned other informal gatherings. On two occasions, a student working at a local coffee shop arranged an open-mike event where many of the cohort gathered to have coffee, provide entertainment, or appreciate the talents of their peers/friends.

These formal and informal gatherings enable the students to know and appreciate each other, making it easier to work collaboratively on assignments and projects. Daunting amounts of work become manageable as students learn to share and support each other while also enjoying their work together. Everyone is appreciated for what they bring to the community rather than being judged on their deficits.

\section{In/out of school}

Partial immersion in the school offers many opportunities to understand school life in ways that are not possible on campus. Beginning the day once a week at 7:45 shows the students how teachers begin, preparing for their upcoming classes, noon hour events, extracurricular activities, and individual students' needs. During the classes they visit during the day, they see diverse teachers' styles, youth in a range of environments including classrooms, hallways, library, and learning support rooms, and experience working with a wide array of students of diverse cultural, racial, ability, gender, and socioeconomic backgrounds. They observe interactions between students, between students and their teachers, and have opportunities to engage with teachers. At the end of the day they have further chances to debrief, ask questions, and gain insights from their peers and instructors. While this is normal routine for teachers, engagement in this 
immediate cycle of reflection and action can be overwhelming and exhausting for preservice teachers. A balance between school time and time on campus is one of the conditions of learning to emerge. The nested structures and ambiguous boundaries featured in complexity exist, overlap and intersect which serves to de-emphasize the setting in favour of the meaning drawn from the learning. As a result, students have time to reflect in ways less influenced by the demands of time and action, gain new ideas and theoretical understandings that they have not gleaned in the school, to talk with each other, and to unwind.

A recent school experience enabled our students to work with high school students in a grade eleven English class who were developing an essay about a novel they had just read. Working one-on-one, they were able to talk with the students, gain an understanding of their interests and abilities, help them delve more deeply into ideas and plan their structure, and model writing process. At the same time, one of the university instructors was present, able to witness their experiences and connect it to further conversations on campus. Also present was a formal practicum student who was just beginning to work with the teacher, who was also able to provide learning and teaching insights.

In another class, high school students in a Contemporary English class were presenting their findings of their previous class's research activity exploring different elements of hip-hop. Our students were able to view their approaches and abilities (as well as gain knowledge of hip-hop) and to observe how the teacher managed group presentations and feedback. Also in the room was a practicum student teacher who, after watching the teacher's lesson, then taught the class for the final 15 minutes. Each aspect of this class gave our students insights into the profession, as well as enabling them to formulate a sense of their own teacher identity.

These examples are just two of many opportunities that are offered to our students each school-based day, learning in the moment. Course instructors come to the school as their schedules allow, creating ever-expanding community with the seminar instructor/teachers but also with other teachers and administrators in the school. This expanding professional learning community offers opportunities and possibilities that are often not planned at the beginning of the term, but emerge because we (instructors and students) are present in the school.

\section{Concluding Thoughts}

Embedded in the TRUVIC experiences are intersecting and complicated layers of knowing, doing and emerging teacher education. We have attempted throughout this paper to interweave the instructors' lived experiences of TRUVIC as a learning system with its theoretical underpinnings drawn from relational ways of knowing and informed by complexity theory. The Indigenous teaching and learning principles provide a compass from which we take direction. These principles are neither arbitrary nor superficial; they emerged from multiple discourses and perspectives about learning and living in the world and are intended to permeate our learning and interactions. Through our involvement in the TRUVIC experience and now in its dissemination, we are not just 
responding to the critiques we shared earlier in this paper, but we are offering insight into and perhaps even advice into how we as teacher educators can provide a learning experience in the process of becoming a teacher. Such a process for student, teacher and instructor alike that is deeply rich and emergent in ways that the traditional system has yet to effectively model. We have not reported evidence from students about the TRUVIC project in this paper as the focus was on a case study of the lived experience of the instructors. However, our beliefs in the project have been verified through multiple exchanges with students. As evidence of this we refer you to Sanford's (2012) website that captures insights on TRUVIC experience from interviews at the university, at the school and on field trips with students, teachers, instructors, school administrators and ministry of education observers.

We have long struggled with the objectivist, control mechanism of teacher education described earlier by Ramiah (2014) that promotes a neo-liberal ideology of competing, working individually and striving for personal advancement even at the cost of others. Yet that struggle has also forced us to examine and consider the centrality of relationships in the process of becoming a teacher. By doing this we embrace, to help articulate, the complex and messy world of teaching that awaits prospective teachers in ways that are personally and professionally meaningful. Students, teachers and teacher educators, as a result of their involvement in the TRUVIC experience, have been empowered and enabled, a welcome alternative to the grinding routine of schooling in which all of us have participated in yet failed to resonate with.

In this paper we have attempted to describe what it was like to transform an aspect of a teacher education program by integrating courses and school experience into a complex learning system. Neighbourly interactions between students were promoted through relational accountability that was legitimized by Indigenous teaching and learning principles. This enabled a relational epistemology to form where being in class shifted from being a student of content for teaching to 'being in' or 'reflect on' the world of teaching and learning (Lysaker \& Furuness, 2011). In this way learning to become a teacher was enacted through practicing respect for peers, teachers and the students they taught, relevance of university course learning to school experiences, reciprocity through shared learning and different insights, and responsibility for own and others learning.

Learning to be a teacher by going to a school where teaching happens has long been a tenet of teacher educators. However, how to learn to become an 'effective' teacher, a 'good' teacher is not a case of simply observing and copying another person or applying theories of learning and teaching. It involves a continuous circular process where both knower and known are brought forth and co-specify each other (Proulx, 2008). In TRUVIC students formed a collective consciousness that observed, became comfortable in a school, in different pedagogical spaces, got to know adolescent students, then volunteered to teach as they saw how they could contribute to the schoolteachers' lessons. This process shifted how students as a cohort and their instructors as a collective described the world of teaching, as they learned to teach with a relational epistemology, as they learned to interact with and bring forth the knowledge of being a teacher from different pedagogical spaces. 


\section{References}

Apps, L. 2007. Artistic process: Demystifying art-making. PhD diss., Simon Fraser Univ.

Bonnet, J. 2006. Stealing fire from the Gods: The complete guide to story for writers and filmmakers, 2nd ed. Studio City, CA: Michael Wiese.

Combs, A. W. 1965. The professional education of teachers: A perceptual view of teacher preparation. Boston: Allyn and Bacon.

Barab, S. A., \& Plucker, J. A. (2002). Smart people or smart contexts? Cognition, ability, and talent development in an age of situated approaches to knowing and learning. Educational Psychologist, $37,165-182$. http://www.tandfonline.com/doi/abs/10.1207/S15326985EP3703 3?journalCode=hedp20\#.VH5EvN $\underline{\text { YkNfA }}$

Belenky, M., Clinchy, B., Goldberger, N., and Tarule, J. (1986). Women's Ways of Knowing. New York: BasicBooks, Inc.

Brouwer, N., \& Korthagen, F. (2005). Can teacher education make a difference? American Educational Research Journal, 42(1), 153-224.

Brownlee, J., \& Berthelsen, D. (2008). Developing relational epistemology through relational pedagogy: New ways of thinking about personal epistemology in teacher education. In M.S. Khine (ed.) Knowing, knowledge and beliefs: Epistemological studies across diverse cultures (pp. 405-422). New York. NY: Springer. Retrieved from http://link.springer.com/chapter/10.1007\%2F978-1-4020-65965 19\#page-1

Buckley, S., Coleman, J., Davison, I., Khan, K. S., Zamora, J., Malick, S., ... Sayers, J. (2009). The educational effects of portfolios on undergraduate student learning: a Best Evidence Medical Education (BEME) systematic review. BEME Guide No. 11. Medical Teacher, 31(4), 282-298. doi:10.1080/01421590902889897. http://www.ncbi.nlm.nih.gov/pubmed/19404891?dopt=Citation

Capra, Fritjof. 1996. The Web of Life: A New Scientific Understanding of Living Systems. Anchor

Capra, F., \& Luigi Luisi, P. (2014). The systems view of life: A unifying vision. New York: Cambridge University Press.

Cochran-Smith, M., \& Zeichner, K. M. (2010). Studying teacher education: The report of the AERA panel on research and teacher education. New York: Routledge.

Cochran-Smith, M., Ell, F., Ludlow, L., \& Aitken, G. (2014). The challenge and promise of complexity theory for teacher education research, Teachers College Record, 116(5), 1-38.

Cormier, D. (2008). Rhizomatic education: Community as curriculum. Innovate: Journal of online education, 4(5). http://www.innovateonline.info/index.php?view=article\&id=550

Davis, B. (2005). Teacher as "consciousness of the collective." Complicity: An International Journal of Complexity and Education, 2(1), 85-88.

Davis, B., \& Sumara, D. (1997). Cognition, complexity, and teacher education. Harvard Educational Review, 67(1), 105-125.

Davis, B., \& Sumara, D. (2006). Complexity and education: Inquires into learning, teaching and research. London: Lawrence Erlbaum.

Davis, B., \& Sumara, D. (2012). Fitting teacher education in/to/for an increasingly complex world. Complicity: An International Journal of Complexity and Education, 9(1), 30-40.

Dewey, J. (1904). The relation of theory to practice in education. The third yearbook of the National Society for the Scientific Study of Education (pp. 9-30). Chicago: University of Chicago Press.

Giles, D. (2011). Relationships always matter: Findings from a phenomenological research inquiry," Australian Journal of Teacher Education, 36(6), 79-91. Retrieved from http://ro.ecu.edu.au/ajte/vol36/iss6/6

Giroux, H. A. (2005). Schooling and the struggle for public life. London: Paradigm Publishers. 
Hopper, T. F. (2013). Emergence in school integrated teacher education for elementary PE teachers: Mapping a complex learning system. In A. Ovens, T. Hopper, \& J. Butler (Eds.), Complexity thinking in physical education: Reframing curriculum, pedagogy and research (pp. 151-163). London: Routledge.

Hopper, T., \& Sanford, K. (2004). Representing multiple perspectives of self-as-teacher: School integrated. Teacher Education Quarterly, 31(2), 57-74.

Hopper, T., \& Sanford, K. (2005). "Teacherly conversations" within school integrated teacher education courses: Creating intersecting communities of practice for transformative education. Montreal: American Education Research Association (AERA).

Hopper, T., \& Sanford, K. (2006). Self-study...so what? Self through SITE as innovative wedge informs program development. In Self-study of teacher education practices Fitzgerald, L., Heston, M., \& Tidwell, D. (Eds.) (pp. 127-134). Cedar Falls, Iowa: University of Northern Iowa. http://resources.educ.queensu.ca/ar/sstep/S-STEP6-2006.pdf

Hopper, T., \& Sanford, K. (2008). Using poetic representation to support the development of teachers' knowledge. Studying Teacher Education, 4(1), 29-45. doi:10.1080/17425960801976339

Horn, J., (2008). Human research and complexity theory. Educational Philosophy and Theory, 40, 130-143. Johnson, S. (2001). Emergence: The connected lives of ants, brains, cities, and software. New York: Scribner.

Kauffmann, S. (1995). At home in the universe: The search for the laws of self-organization and complexity. Oxford: Oxford University Press.

Kirkness, V. J., \& R. Barnhardt. (1991). First Nations and higher education: The four R's - respect, relevance, reciprocity, responsibility. Journal of American Indian Education, 30(3). Retrieved from http://jaie.asu.edu/v30/V30S3fir.htm

Korthagen, F., Loughran, J., \& Russell, T. (2006). Developing fundamental principles for teacher education programs and practices. Teaching and Teacher Education, 22, 1020-1041. http://www.sciencedirect.com/science/article/pii/S0742051X06000618

Lave \& Wenger, E., J. (1991). Situated learning: Legitimate peripheral participation. New York: Cambridge University Press.

Loughran, J. J. (2006). Developing a pedagogy of teacher education: understanding teaching and learning about teaching. London; New York: Routledge.

Lysaker, J. T., \& Furuness, S. (2011). Space for transformation: Relational, dialogic pedagogy. Journal of Transformative Education, 9(3), 183-197.

Mason, M. (2008). What is complexity theory and what are its implications for educational change? Educational Philosophy and Theory, 40(1), 35-49.

Morrison, K. (2008). Educational philosophy and the challenge of complexity theory. Educational Philosophy and Theory, 40, 19-34. http://www.tandfonline.com/doi/abs/10.1111/j.14695812.2007.00394.x\#.VH5DyNYkNfA

Proulx, J. (2008). Some differences between Maturana and Varela's theory of cognition and constructivism. Complicity: An International Journal of Complexity and Education, 5(1), 11-26.

Ramiah, A. R. (2014). Complexity thinking in ALL practice. Journal of Academic Language \& Learning, 8(3), 62-71. http://journal.aall.org.au/index.php/jall/article/view/350

Riley-Taylor, E. (2002). Ecology, spirituality, and education: Curriculum for relational knowing. New York: Peter Lang.

Russell, T., McPherson, S., \& Martin, A. (2001). Coherence and collaboration in teacher education reform. Canadian Journal of Education, 26(1), 37-55.

Salomon, G. (Ed.). (1993). Distributed cognitions: Psychological and educational considerations. Cambridge, England: Cambridge University Press.

Sanford, K. (2012). TRUVIC. Google Sites. Retrieved April 26, 2015, from https://sites.google.com/site/truvicproject/

Sanford, K., Williams, L., Hopper, T., \& McGregor, C. (2012). Indigenous principles informing teacher education: What we have learned. In Education, 18(2), 1-12. 
Schleicher, A. (2014). The case for 21st-century learning. Retrieved from http://www.oecd.org/general/thecasefor21st-centurylearning.htm

Siemens, G., \& Matheos, K. (2012). Systemic changes in higher education. In Education, 18(1), 3-18.

Stake, R. (2005). Case studies. In N. K. Denzin \& Y. S. Lincoln (Eds.), The handbook on qualitative research (3rd ed., pp. 443-466). Chicago and London: SAGE Publications.

Trilling, B., \& Fadel, C. (2009). 21st century skills: learning for life in our times. San Francisco: Jossey-Bass. Wideen, Mayer-Smith, J., \& Moon, B. (1998). A critical analysis of the research on learning to teach: Making the case for an ecological perspective on inquiry. Review of Educational Research, 68(2), 130178.

Wilson, S. (2007). Guest editorial: What is an Indigenist Research Paradigm? Canadian Journal of Native Education, 30, 193-195.

Wilson, S. (2008). Research is ceremony: Indigenous research methods. Black Point, Nova Scotia: Fernwood Publishing.

\section{About the Author/s}

Kathy Sanford is a Professor at the University of Victoria in the Department of Curriculum \& Instruction. Her research interests include teacher education, ePortfolios as alternative forms of learning/assessment, and multiliteracies. Her contact email is ksanford@uvic.ca.

Tim Hopper is an associate professor in the School of EPHE, Faculty of Education. His scholarly work focuses on teacher education and physical education. His research uses complexity thinking as a theoretical frame to explore student learning in relation to ePortfolios, video gaming and teacher education practices. His contact email is thopper@uvic.ca.

Lisa J. Starr is an Assistant professor at McGill University in the Department of Integrated Studies in Education (DISE) and the current president of the Canadian Association for the Study of Women and Education Her current research focus is the use collaborative inquiry and self-study as means to investigate, understand and make meaning of $21^{\text {st }}$ century leading and learning. Her contact email is lisa.starr2@mcgill.ca.

(c) Copyright 2015. The authors, Kathy Sanford, Tim Hopper and Lisa Starr, assign to the University of Alberta and other educational and non-profit institutions a non-exclusive license to use this document for personal use and in courses of instruction provided that the article is used in full and this copyright statement is reproduced. The authors also grant a non-exclusive license to the University of Alberta to publish this document in full on the World Wide Web, and for the document to be published on mirrors on the World Wide Web. Any other usage is prohibited without the express permission of the authors. 